\title{
Regulation of Intracellular Calcium by Endoplasmic Reticulum Proteins in Small Intestinal Interstitial Cells of Cajal
}

\author{
Chan Guk Park, ${ }^{1}$ Mei Jin Wu, ${ }^{2}$ Chansik Hong, ${ }^{2}$ Ju Yeon Jo, ${ }^{1}$ Han Yi Jiao, ${ }^{2}$ Hyun Park, ${ }^{3}$ Jae Yeoul Jun, ${ }^{2}$ and Seok Choi ${ }^{2 *}$ \\ ${ }^{I}$ Department of Internal Medicine, College of Medicine, Chosun University, Gwangju, Korea; ${ }^{2}$ Department of Medicine, Graduate School, Chosun \\ University, Gwangju, Korea; and ${ }^{3}$ Department of Physiology, College of Medicine, Chosun University, Gwangju, Korea
}

\begin{abstract}
Background/Aims
We investigated the role of representative endoplasmic reticulum proteins, stromal interaction molecule 1 (STIM1), and store-operated calcium entry-associated regulatory factor (SARAF) in pacemaker activity in cultured interstitial cells of Cajal (ICCS) isolated from mouse small intestine.

\section{Methods}

The whole-cell patch clamp technique applied for intracellular calcium ions $\left(\left[\mathrm{Ca}^{2+}\right]_{i}\right)$ analysis with STIM1 or SARAF overexpressed cultured ICCs from mouse small intestine.

\section{Results}

In the current-clamping mode, cultured ICCs displayed spontaneous pacemaker potentials. External carbachol exposure produced tonic membrane depolarization in the current-clamp mode, which recovered within a few seconds into normal pacemaker potentials. In STIM1-overexpressing cultured ICCs pacemaker potential frequency was increased, and in SARAF-overexpressing ICCs pacemaker potential frequency was strongly inhibited. The application of gadolinium (a non-selective cation channel inhibitor) or a $\mathrm{Ca}^{2+}$-free solution to understand Orai channel involvement abolished the generation of pacemaker potentials. When recording intracellular $\mathrm{Ca}^{2+}$ concentration with Fluo 3-AM, STIM1-overexpressing ICCS showed an increased number of spontaneous intracellular $\mathrm{Ca}^{2+}$ oscillations. However, SARAF-overexpressing ICCs showed fewer spontaneous intracellular $\mathrm{Ca}^{2+}$ oscillations.
\end{abstract}

\section{Conclusion}

Endoplasmic reticulum proteins modulated the frequency of pacemaker activity in ICCS, and levels of STIM1 and SARAF may determine slow wave patterns in the gastrointestinal tract.

\section{(J Neurogastroenterol Motil 2018;24:128-137)}

\section{Key Words}

Interstitial cells of Cajal; Intestinal motility; Stromal interaction molecule 1; Store-operated calcium entry-associated regulatory factor

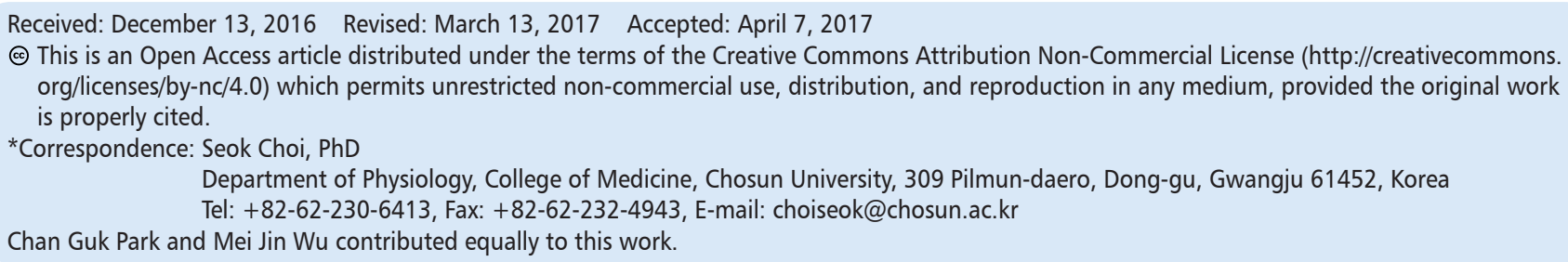




\section{Introduction}

Various cellular functions such as contraction, proliferation, neurotransmission, and exocytosis are regulated by intracellular calcium ions $\left(\left[\mathrm{Ca}^{2+}\right]_{\mathrm{i}}\right) .^{1-4}$ Normally, $\left[\mathrm{Ca}^{2+}\right]_{\mathrm{i}}$ exists in intracellular stores such as the endoplasmic reticulum (ER) and mitochondria. There are 2 ways to increase $\left[\mathrm{Ca}^{2+}\right]_{\mathrm{i}}$ : the influx of $\mathrm{Ca}^{2+}$ ions through the plasma membrane (PM) or by release from intracellular stores. ${ }^{5-7}$

The activation of receptors on the PM releases $\left[\mathrm{Ca}^{2+}\right]_{\mathrm{i}}$ from the $\mathrm{ER}$ and then activates $\mathrm{Ca}^{2+}$ channels at the PM. This process is called store-operated $\mathrm{Ca}^{2+}$ entry (SOCE). It is well known that SOCE is the primary mechanism for $\mathrm{Ca}^{2+}$ signaling and homeostasis. ${ }^{8}$ Many reports have suggested the involvement of diverse proteins in SOCE activity. Until now, stromal interaction molecule (STIM) and Orai proteins are the most important elements for SOCE activity. ${ }^{9-13}$ STIM is an ER protein and depletion of $\mathrm{Ca}^{2+}$ in ER can lead to Orai-STIM binding. This opens Orai channels in the PM and results in $\mathrm{Ca}^{2+}$ entry. ${ }^{14,15}$ Recently, an interesting ER protein, store-operated calcium entry-associated regulatory factor (SARAF), was reported. SARAF plays an important role in preventing excessive $\mathrm{Ca}^{2+}$ influx. ${ }^{16}$ However, the exact role of SARAF in functional cells has not been established.

The gastrointestinal (GI) tract shows spontaneous contraction that is evoked by periodic membrane depolarizations called slow waves. There has been increasing evidence that interstitial cells of Cajal (ICCs) are pacemaking cells that generate slow waves. ${ }^{17-20}$ ICCs produce spontaneous electrical activity (pacemaker activity) that is transmitted into smooth muscle cells through gap junctions. ${ }^{21}$ Although the exact mechanisms underlying these events are still not understood, many reports indicate that periodic $\mathrm{ER} \mathrm{Ca}^{2+}$ oscillations are involved in producing ICC pacemaker activity. ${ }^{22,23}$ This implicates $\left[\mathrm{Ca}^{2+}\right]_{\mathrm{i}}$ as an essential component that enables the production of pacemaker activity in ICCs. However, to date, it is not known how $\left[\mathrm{Ca}^{2+}\right]_{\mathrm{i}}$ is regulated in ICCs. Therefore, we suggest that 2 ER proteins, STIM and SARAF, could be regulators of $\left[\mathrm{Ca}^{2+}\right]_{\mathrm{i}}$, and that ICC pacemaker activity was modulated by those ER proteins in this study.

\section{Materials and Methods}

\section{Ethics}

All experiments were carried out according to the Guiding
Principles for the Care and Use of Animals approved by the ethics committee in Chosun University and the National Institutes of Health Guide for the Care and Use of Laboratory Animals. Every effort was made to minimize the number of animals used and their suffering.

\section{Solutions and Drugs}

Cultured ICCs from small intestine were bathed in a solution containing $5 \mathrm{mM} \mathrm{KCl}, 135 \mathrm{Mm} \mathrm{NaCl}, 2 \mathrm{mM} \mathrm{CaCl}, 10 \mathrm{mM}$ glucose, $1.2 \mathrm{mM} \mathrm{MgCl}_{2}$, and $10 \mathrm{mM} \mathrm{HEPES}$, adjusted to $\mathrm{pH}$ 7.2 with Tris. The pipette solution contained $140 \mathrm{mM} \mathrm{KCl,} 5 \mathrm{mM}$ $\mathrm{MgCl}_{2}$, 2.7 mM K $\mathrm{K}_{2}$ ATP, $0.1 \mathrm{mM} \mathrm{Na} \mathrm{m}_{2} \mathrm{GTP}, 2.5 \mathrm{mM}$ creatine phosphate disodium, $5 \mathrm{mM}$ HEPES, and $0.1 \mathrm{mM}$ EGTA, adjusted to $\mathrm{pH} 7.2$ with Tris.

Carbachol $(\mathrm{CCh})$ and gadolinium chloride were purchased from Sigma Chemical Co (St. Louis, MO, USA). All drugs were dissolved in distilled water or dimethyl sulfoxide (DMSO) to prepare stock solutions (10 or $100 \mathrm{mM}$ ), and were either added to the bath solution or applied to whole-cell preparations by superfusion. The final concentration of DMSO was less than $0.05 \%$.

\section{Preparation of Cells and Tissues}

ICR mice (2-3 day-old) of either sex were anesthetized with ether and euthanized by cervical dislocation. After cervical dislocation, an abdominal incision was made and the entire small intestine was removed. The small intestines from $1 \mathrm{~cm}$ below the pyloric ring to the cecum were removed and opened along the mesenteric border. The luminal contents were washed away with Krebs-Ringer bicarbonate solution. The tissues were fixed with pins to a Sylgard dish and the mucosa was removed by sharp dissection. Strips from small intestinal muscle layer were equilibrated in $\mathrm{Ca}^{2+}$-free KrebsRinger bicarbonate solution for 30 minutes and cells were agitated with an enzyme solution containing $1.3 \mathrm{mg} / \mathrm{mL}$ collagenase (Worthington Biochemical Co, Lakewood, NJ, USA), $2 \mathrm{mg} / \mathrm{mL}$ bovine serum albumin (Sigma Chemical Co), $2 \mathrm{mg} / \mathrm{mL}$ trypsin inhibitor (Sigma Chemical Co), and $0.27 \mathrm{mg} / \mathrm{mL}$ ATP. Cells were plated onto sterile glass coverslips coated with murine collagen (2.5 $\mu \mathrm{g} / \mathrm{mL}$; Falcon/BD) in $35 \mathrm{~mm}$ culture dishes. The cells were then cultured at $37^{\circ} \mathrm{C}$ in a $95 \% \mathrm{O}_{2} / 5 \% \mathrm{CO}_{2}$ incubator in smooth muscle growth medium (Clonetics Corp, San Diego, CA, USA) supplemented with $2 \%$ antibiotics/antimycotics (Gibco, Grand Island, NY, USA) and murine stem cell factor ( $5 \mathrm{ng} / \mathrm{mL}$; Sigma Chemical $\mathrm{Co})$. 


\section{Patch Clamp Experiments}

The whole-cell configuration of the patch-clamp technique was used to record membrane potentials (current clamp) from cultured ICCs. For transfected ICCs, electrophysiological recordings were performed 24 hours after transfection of the full-length STIM1, SARAF, or empty pcDNA vectors. Potentials were amplified with an Axopatch 200B (Axon Instruments, Foster, CA, USA). Command pulse was applied using an IBM-compatible personal computer and pClamp software (version 9.2; Axon Instruments). The data were filtered at $5 \mathrm{kHz}$ and displayed on a computer monitor. Results were analyzed using pClamp and Sigma plot (version 9.0) software. All experiments were performed at $30^{\circ} \mathrm{C}$.

\section{Clones Preparation and Transfection}

The STIM1 and SARAF expression constructs were obtained from Thermo Fisher Scientific, Seoul, South Korea (SARAF Mm00509538 m1 and STIM1 Mm01158413 m1). STIM1 was cloned into pcDNA7.1 GFP at EcoRI (5') and NotI sites (3') sites, and SARAF was cloned into pCMV6-AC-myc plasmid at HindIII (5') and MIuI (3') sites, creating a Myc tag at the C-terminus. After 24 hours of ICC culture, transfection of the resulting STIM1, SARAF, and empty pcDNA vectors was performed with Lipofectamine 2000 (Thermo Fisher scientific). All cDNA concentrations were measured with a Colibri Spectrometer (TitertekBerthold, Pforzheim, Germany).

\section{Reverse Transcription-Polymerase Chain Reaction}

Cells with typical ICC morphology, ie, triangular or spindle shapes with multiple branches were collected (about 2-5 cells) by applying negative pressure to the cell in contact with a recording pipette. After lifting the cell out of the bath, it was immediately expelled from the pipette into phosphate-buffered saline by applying positive pressure. The cells were spun down at $5000 \times g$ for 5 minutes before lysis. Total RNA was isolated using TRIzol reagent (Invitrogen, Carlsbad, CA, USA) according to the manufacturer specifications. Reverse transcription was performed using Superscript One-Step reverse transcription-polymerase chain reaction (RT-PCR) with Platinum Taq (Invitrogen) at $45^{\circ} \mathrm{C}$ for 30 minutes followed by $94^{\circ} \mathrm{C}$ for 5 minutes for denaturation of the cDNA hybrid. The thermal cycler was programmed such that cDNA synthesis was immediately followed by PCR amplification. The primers used are presented in Table. The following 3-step process was executed for 38 cycles: $94^{\circ} \mathrm{C}$ for 30 seconds for denaturation, $60^{\circ} \mathrm{C}$ for 30 seconds for annealing, and $72^{\circ} \mathrm{C}$ for 30 seconds for the extension. The PCR products were visualized on a $2 \%$ agarose gel following electrophoresis and ethidium bromide staining.

\section{Measurement of Intracellular Calcium lons Concentration}

Changes in $\left[\mathrm{Ca}^{2+}\right]_{\mathrm{i}}$ concentration were monitored using Fluo 3-AM, which was initially dissolved in DMSO and stored at $-20^{\circ} \mathrm{C}$. ICCs cultured on coverslips $(25 \mathrm{~mm})$ were rinsed twice with a bath solution (in $\mathrm{mM}: \mathrm{KCl} 5, \mathrm{NaCl} 135, \mathrm{CaCl}_{2}$ 2, glucose $10, \mathrm{MgCl}_{2}$ 1.2, and HEPES 10, adjusted to $\mathrm{pH} 7.4$ with Tris), incubated in the bath solution containing $5 \mu \mathrm{M}$ Fluo 3-AM with $5 \% \mathrm{CO}_{2}-95 \% \mathrm{O}_{2}$ at $37^{\circ} \mathrm{C}$ for 20 minutes, rinsed 2 more times with the bath solution, mounted on a perfusion chamber, and scanned every second with a confocal microscope $(\times 200$, Fluoview 300; Olympus, Tokyo, Japan). Fluorescence was excited at $488 \mathrm{~nm}$, and emitted light was observed at $515 \mathrm{~nm}$. During scanning of $\mathrm{Ca}^{2+}$ imaging, the temperature of the perfusion chamber containing the

Table. Nucleotide Sequences of the Primers Used for Reverse Transcription-Polymerase Chain Reaction

\begin{tabular}{|c|c|c|c|}
\hline Gene & Sequences & Accession No. & Size (bp) \\
\hline ANO1 & $\begin{array}{l}\text { (F) AGG CCA AGT ACA GCA TGG GTA TCA } \\
\text { (R) AGT ACA GGC CAA CCT TCT CAC CAA }\end{array}$ & NM_178642 & 213 \\
\hline Myosin & $\begin{array}{l}\text { (F) GAGAAAGGAAACACCAAGGTCAAGC } \\
\text { (R) AACAAATGAAGCCTCGTTTCCTCTC }\end{array}$ & NM_010860 & 264 \\
\hline PGP 9.5 & $\begin{array}{l}\text { (F) GCCAACAACCAAGACAAGCTGGAA } \\
\text { (R) GCCGTCCACGTTGTTGAACAGAAT }\end{array}$ & AF 172334 & 213 \\
\hline STIM1 & $\begin{array}{l}\text { (F) AAGAGTCTACCGAAGCAG } \\
\text { (R) GTGCTATGTTTCACTGTTGG }\end{array}$ & NM_009287 & 199 \\
\hline SARAF & $\begin{array}{l}\text { (F) CAACGACCCTGACAGAATAC } \\
\text { (R) CACAGCTCACCACAGTTT }\end{array}$ & NM_026432 & 251 \\
\hline
\end{tabular}

ANO1, anoctamin-1; PGP 9.5, protein gene product 9.5; STIM1, stromal interaction molecule 1; SARAF, store-operated calcium entry-associated regulatory factor. 
cultured ICCs was maintained at $30^{\circ} \mathrm{C}$. The variations of intracellular $\mathrm{Ca}^{2+}$ fluorescence emission intensity were expressed as $\mathrm{F} 1 / \mathrm{F} 0$, where $\mathrm{F} 0$ represents the intensity of the first image and counted the peak points as frequency.

\section{Statistical Methods}

Data are expressed as the mean $\pm \mathrm{SE}$. Differences in the data were evaluated by ANOVA followed by a post hoc test. Differences with $P$-values less than 0.05 were considered statistically significant. The $n$ values reported in the text refer to the number of cells used in the patch-clamp experiments.

\section{Results}

\section{Effect of Carbachol on Pacemaker Potentials in Cultured Interstitial Cells of Cajal}

ICCs were identified with an immunofluorescence kit, and had a distinctive morphology that was easily recognized in cultures (data not shown). ${ }^{23}$ We performed the electrophysiological recording from cultured ICCs under the current mode $(I=0)$. Under the current clamp mode at $30^{\circ} \mathrm{C}$, ICCs showed spontaneous regular pacemaker potentials (Fig. 1A). CCh treatment (10 nM), which activates acetylcholine receptors, depolarized the resting membrane potential and decreased the amplitude of the pacemaker potential (Fig. 1B). Under control conditions with the current-clamp mode, the resting membrane potential and pacemaker potential frequency were $-59.6 \pm 2.6 \mathrm{mV}$ and $14.7 \pm 0.8$ cycles/minute, respectively. In the presence of $\mathrm{CCh}$, the resting membrane potential and pacemaker potential frequency were $-39.4 \pm 3.6 \mathrm{mV}$ and $2.6 \pm 4.3$ cycles/minute, respectively. The summarized values and a bar graph of the effects of $\mathrm{CCh}$ on pacemaker potential are shown in Figures $1 \mathrm{C}$ and $1 \mathrm{D}(\mathrm{n}=5)$.

\section{Increased Frequency of Pacemaker Activity by Stromal Interaction Molecule 1 Overexpression in Cultured Interstitial Cells of Cajal}

To determine the role of STIM1, STIM1 cDNA was overexpressed in cultured ICCs. Under the current clamp mode at $30^{\circ} \mathrm{C}$, pcDNA-overexpressing ICCs showed spontaneous regular pacemaker potentials (Fig. 2A), and pacemaker potential frequency was increased in STIM1-overexpressing ICCs. Further, the regular
A

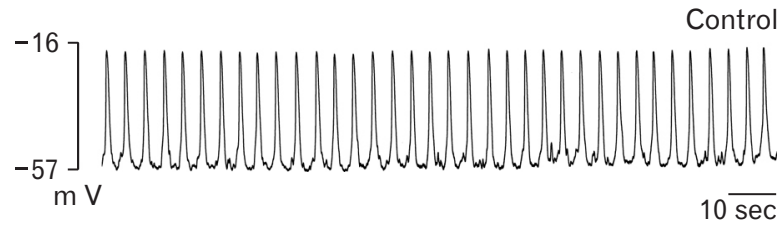

B

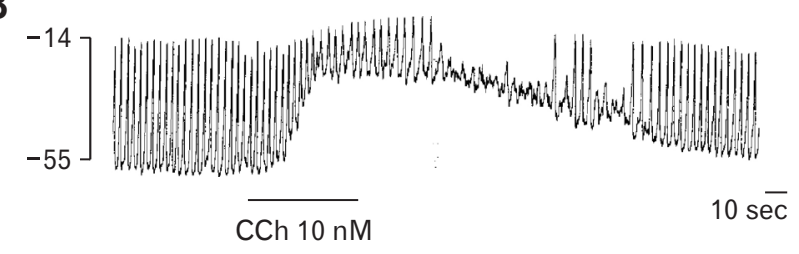

D

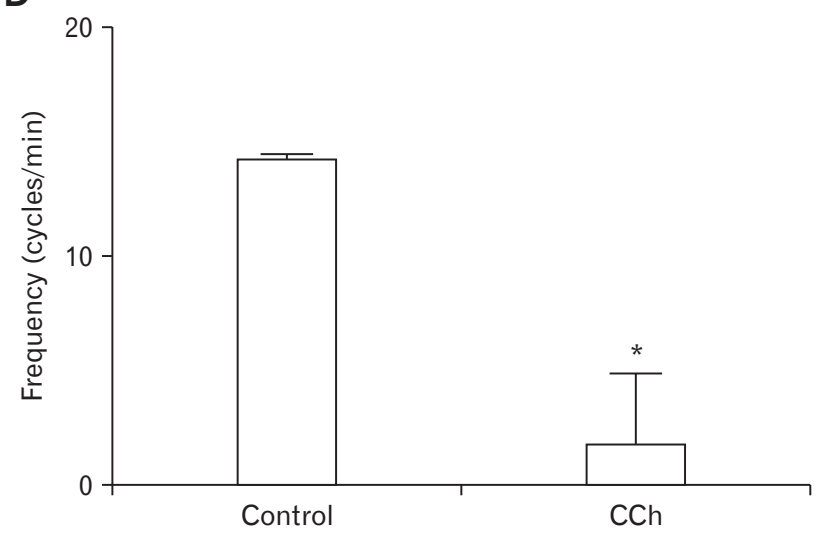

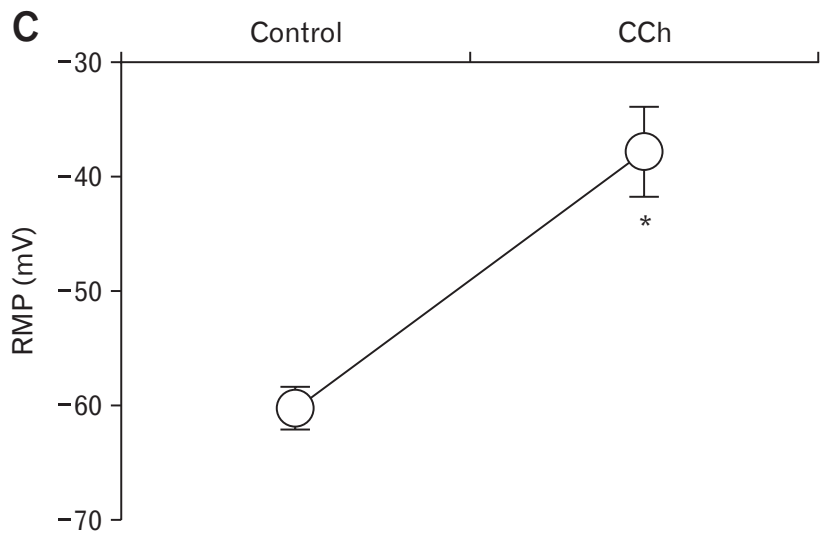

Figure 1. Effects of carbachol (CCh) treatment on pacemaker potentials recorded in cultured interstitial cells of Cajal (ICCs) from mouse small intestine. (A) Pacemaker potentials of ICCs in current clamping mode $(I=0)$. The vertical solid lines represent the scale of pacemaker potential amplitudes, and the horizontal solid lines represent the scale of pacemaker potential recording duration. (B) Pacemaker potentials of ICCs exposed to $\mathrm{CCh}(10 \mathrm{nM})$ in the current clamping mode $(I=0)$. Cellular responses to CCh are summarized in $(C)$ and $(\mathrm{D})$. The bars represent mean values \pm SE. Asterisks represent significant differences from untreated control cells (Control) $\left({ }^{\star} P<0.01\right)$. RMP, resting membrane potentials. 
A
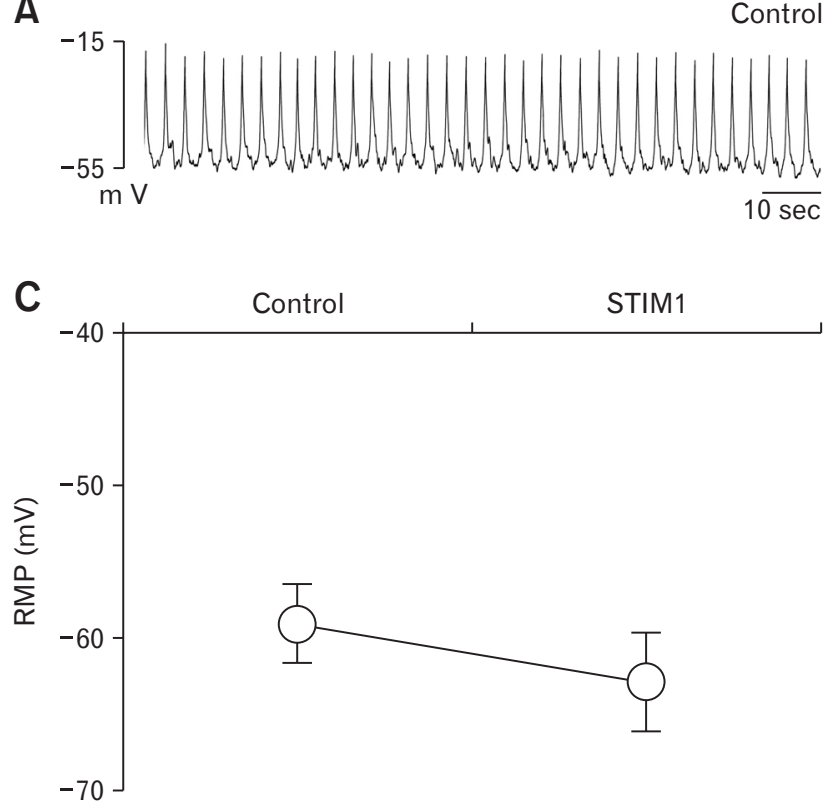

B

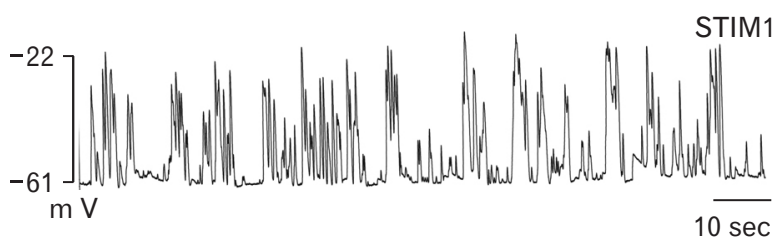

D

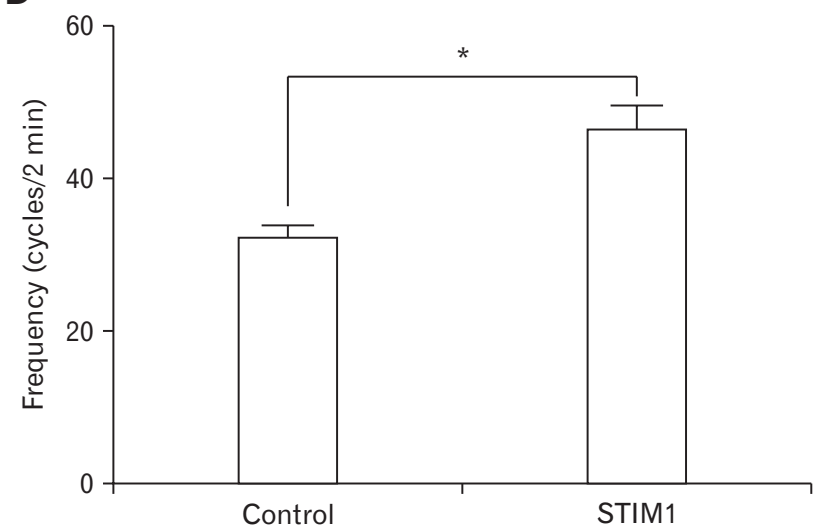

Figure 2. Pacemaker potentials recorded in control or stromal interaction molecule 1 (STIM1)-overexpressing cultured interstitial cells of Cajal (ICCs) from mouse small intestines. (A) Pacemaker potentials of ICCs in the current clamping mode $(I=0)$. Vertical solid lines represent the scale of pacemaker potential amplitudes, and horizontal solid lines represent the scale of pacemaker potential recording duration. (B) Pacemaker potentials of STIM1-overexpressing ICCs in current-clamping mode $(I=0)$. Pacemaker potential responses in STIM1-overexpressing ICCs are summarized in (C) and (D). The bars represent mean values \pm SE. Asterisks represent significant differences from empty vector-expressing control cells (Control) $\left({ }^{*} P<0.01\right)$. RMP, resting membrane potentials.

pattern of pacemaker activity observed in normal ICCs became irregular and a spike-fused shape was observed (Fig. 2B). Under control conditions in pcDNA-transfected ICCs, the resting membrane potentials and frequency of pacemaker potentials were -57.4 $\pm 2.9 \mathrm{mV}$ and $33.6 \pm 6.2$ cycles $/ 2$ minutes, respectively. In the case of STIM- overexpressing ICCs, the resting membrane potential and frequency of pacemaker potentials were $-62.4 \pm 5.4 \mathrm{mV}$ and $48.6 \pm 5.2$ cycles $/ 2$ minutes, respectively. The summarized values and a bar graph with results from STIM1-transfected ICCs are shown in Figures 2C and 2D $(n=8)$.

\section{Decreasing Frequency of Pacemaker Activity by Store-operated Calcium Entry-associated Regulatory Factor Overexpression in Cultured Interstitial Cells of Cajal}

To determine the role of SARAF, SARAF cDNA was overexpressed in cultured ICCs. In the current clamp mode at $30^{\circ} \mathrm{C}$, pcDNA-overexpressing ICCs showed spontaneous regular pacemaker potentials (Fig. 3A). In case of SARAF overexpressed ICCs, the frequency of pacemaker activity was dramatically inhib- ited (Fig. 3B). Under control conditions, resting membrane potentials and frequency of pacemaker potentials in ICCs were $-58.1 \pm$ $4.1 \mathrm{mV}$ and $31.8 \pm 3.4$ cycles $/ 2$ minutes, respectively. In the case of SARAF-overexpressing ICCs, the resting membrane potential and frequency of pacemaker potentials were $-64.8 \pm 5.5 \mathrm{mV}$ and 7.6 \pm 2 cycles/2 minutes, respectively. The summarized values and a bar graph with results from SARAF-transfected ICCs are shown in Figures $3 \mathrm{C}$ and $3 \mathrm{D}(\mathrm{n}=9)$.

\section{Molecular Expression of Stromal Interaction Molecule 1 or Store-operated Calcium Entry-associated Regulatory Factor with Interstitial Cells of Cajal}

In the present study, RT-PCR analysis revealed the mRNA transcripts for STIM1 and SARAF in whole mount cultured small intestinal cells in Fig. 4A. After pick up cells, we checked only anoctamin-1 (ANO1) positive samples. Those samples showed STIM1 and SARAF were detected in ANO1 positive ICCs isolated from the culture of the small intestine (Fig. 4A). 
A

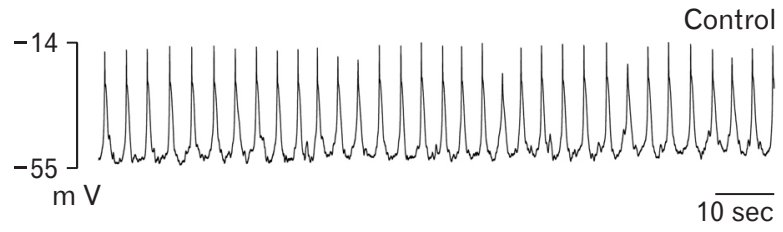

B

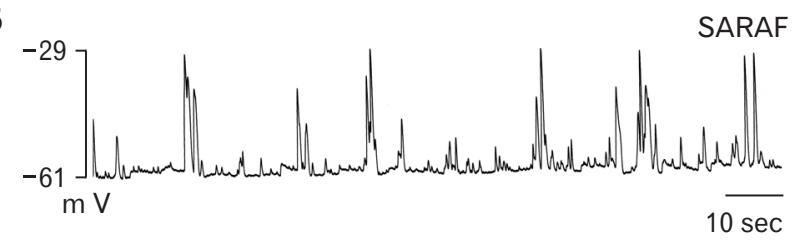

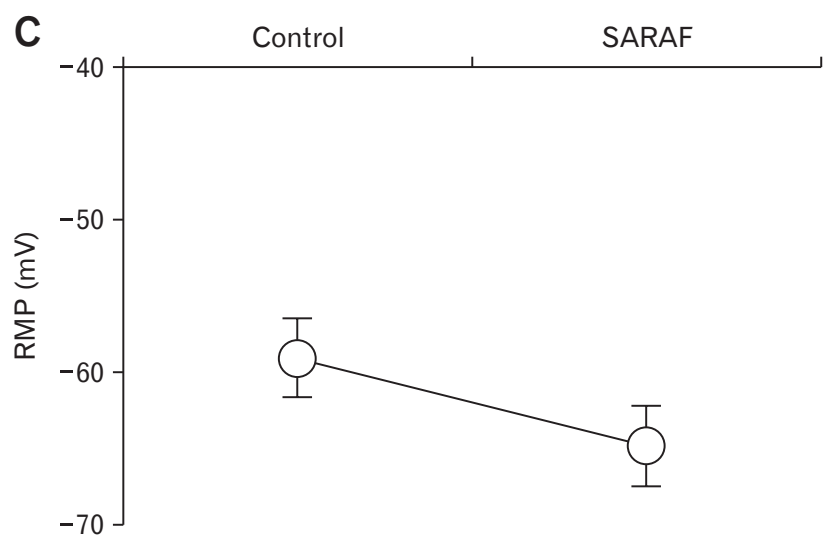

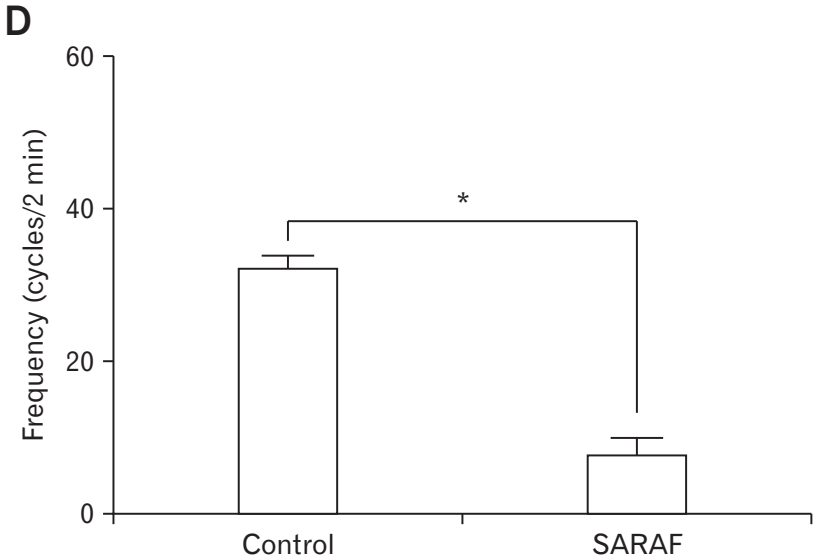

Figure 3. Pacemaker potentials recorded in control or store-operated calcium entry-associated regulatory factor (SARAF)-overexpressing cultured interstitial cells of Cajal (ICCs) from mouse small intestine. (A) Pacemaker potentials of ICCs in the current clamping mode ( $I=0)$. Vertical solid lines represent the scale of pacemaker potential amplitudes, and horizontal solid lines represent the scale of pacemaker potential recording duration. (B) Pacemaker potentials of SARAF-overexpressing ICCs in the current clamping mode $(I=0)$. Pacemaker potential responses in SARAF-overexpressing ICCs are summarized in (C) and (D). The bars represent mean values \pm SE. Asterisks represent significant differences from empty vector-expressing control cells $(\mathrm{Control})\left({ }^{*} \mathrm{P}<0.01\right)$. RMP, resting membrane potentials.

\section{Effect of Gadolinium or a Calcium lons-free Solution on Pacemaker Activity in Cultured Interstitial Cells of Cajal}

To understand the role of extracellular $\mathrm{Ca}^{2+}$ entry mechanism on pacemaker activity, we tested the effect of treating cultured ICCs with gadolinium $\left(\mathrm{Gd}^{3+} ; 10 \mu \mathrm{M}\right)$ or a $\mathrm{Ca}^{2+}$-free solution at $30^{\circ} \mathrm{C}$. In the presence of $\mathrm{Gd}^{3+}$ or a $\mathrm{Ca}^{2+}$-free solution, the ICC pacemaker potential frequency was completely blocked (Fig. 4B and 4C). The summarized values and a bar graph with results of treating ICCs with $\mathrm{Gd}^{3+}$ or a $\mathrm{Ca}^{2+}$-free solution are shown in Figures $4 \mathrm{D}$ and $4 \mathrm{E}$ $(n=6)$.

\section{Modulation of Intracellular Calcium lons Intensity by Overexpressing Stromal Interaction Molecule 1 or Store-operated Calcium Entry-associated Regulatory Factor in cultured Interstitial Cells of Cajal}

To directly determine the role of STIM1 or SARAF on $\left[\mathrm{Ca}^{2+}\right]_{\mathrm{i}}$, we examined $\left[\mathrm{Ca}^{2+}\right]_{\mathrm{i}}$ oscillation in STIM1- or SARAF-transfected ICCs. Spontaneous $\left[\mathrm{Ca}^{2+}\right]_{\mathrm{i}}$ oscillations were observed in pcDNA- transfected ICCs loaded with Fluo 3-AM; the time series data show these spontaneous regular $\left[\mathrm{Ca}^{2+}\right]_{\mathrm{i}}$ oscillations (Fig. $5 \mathrm{~A}$ ) at $30^{\circ} \mathrm{C}$. In the case of STIM1-overexpressing ICCs, the frequency of $\left[\mathrm{Ca}^{2+}\right]_{\mathrm{i}}$ oscillations was increased (Fig. 5B). However, SARAFoverexpressing ICCs showed a decreased frequency of $\left[\mathrm{Ca}^{2+}\right]_{\mathrm{i}}$ oscillations compared to the control (Fig. $5 \mathrm{C}$ ); the time series data are summarized in Figure 5D $(\mathrm{n}=8)$.

\section{Discussion}

Recently, many studies have attempted to determine which channel generates electrical pacemaker activity of ICCs in the GI tract. Some of the proposed channels include non-selective cation, $\mathrm{Ca}^{2+}$-activated $\mathrm{Cl}^{-}$or T-type $\mathrm{Ca}^{2+}$ channels, among others. ${ }^{25-28}$ However, there is no argument that $\left[\mathrm{Ca}^{2+}\right]_{\mathrm{i}}$ oscillations are the initial mechanism for generating pacemaker activity. ${ }^{28}$ Periodic $\left[\mathrm{Ca}^{2+}\right]_{\mathrm{i}}$ release from $\mathrm{Ca}^{2+}$ stores produces $\left[\mathrm{Ca}^{2+}\right]_{\mathrm{i}}$ oscillations in ICCs and these actions are considered to be the primary pacemaker activity. To date, it is not fully known how $\left[\mathrm{Ca}^{2+}\right]_{\mathrm{i}}$ release is modulated. In this study, by examining electrical pacemaker activity in STIM1- 
A

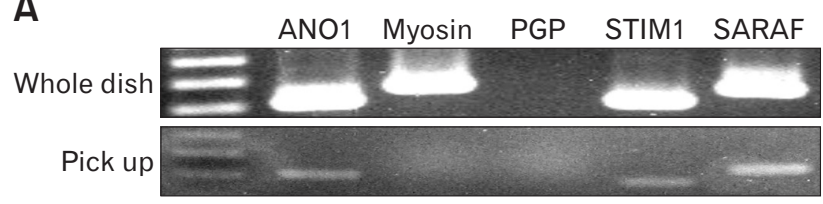

B

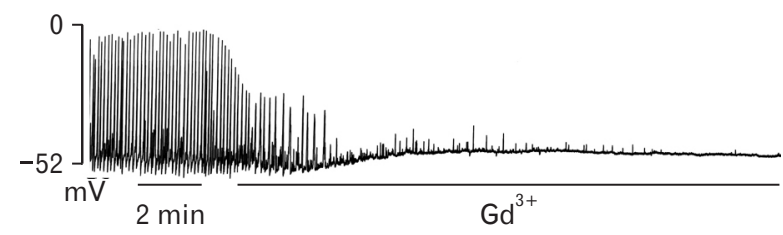

C

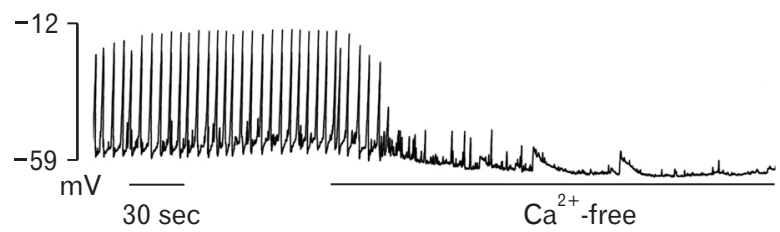

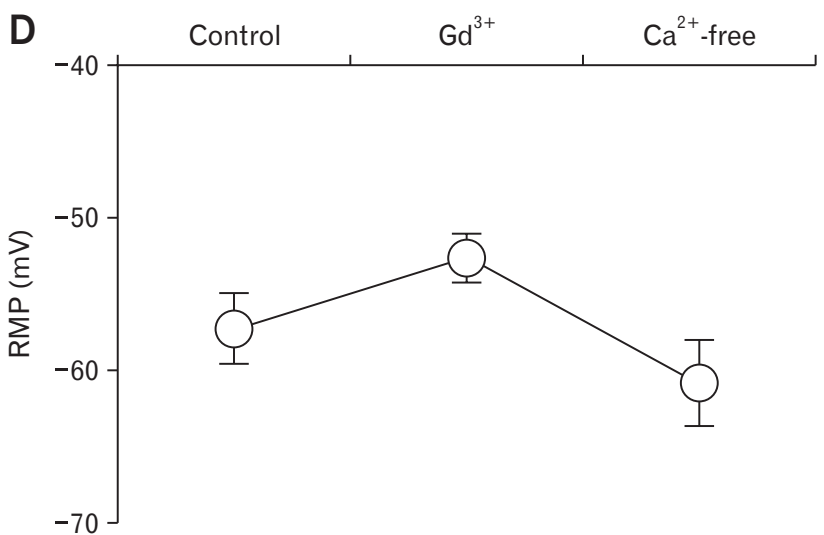

E

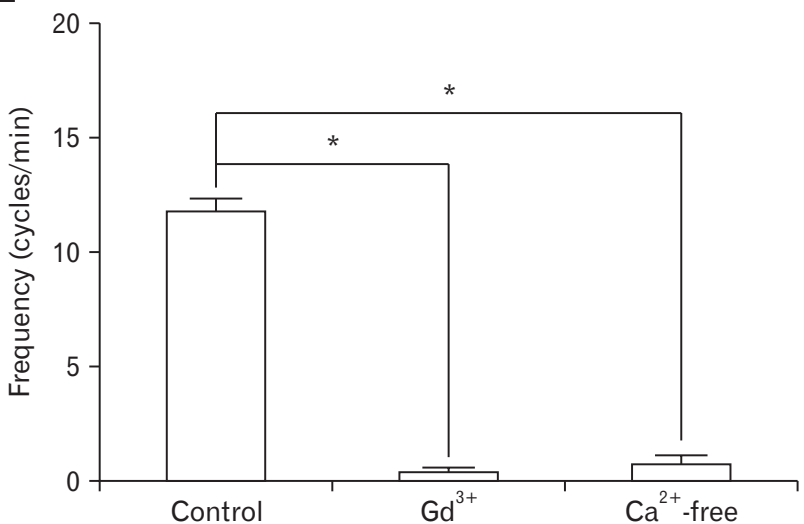

Figure 4. Molecular expression of stromal interaction molecule 1 (STIM1) and store-operated calcium entry-associated regulatory factor (SARAF), and effects of gadolinium or an external calcium ions $\left(\mathrm{Ca}^{2+}\right)$-free solution on pacemaker potentials in cultured interstitial cells of Cajal (ICCs) from mouse small intestine. (A) Reverse transcription-polymerase chain reaction (RT-PCR) detected the transcripts for STIM1 and SARAF in whole mounted cultured cells (upper panel) and in anoctamin-1 (ANO1) positive cultured ICCs (lower panel). (B) Gadolinium exposure (Gd ${ }^{3+}$; $10 \mu \mathrm{M}$ ) abolished the generation of pacemaker potentials in cultured ICCs. Vertical solid lines represent the scale of pacemaker potential amplitudes and horizontal solid lines represent the scale of pacemaker potential recording duration. (C) External $\mathrm{Ca}^{2+}$-free solution exposure inhibited pacemaker potential generation. Pacemaker potential responses to $\mathrm{Gd}^{3+}$ or external $\mathrm{Ca}^{2+}$-free solution exposure are summarized in (D) and (E). The bars represent mean values $\pm \mathrm{SE}$. Asterisks represent significant differences from untreated control cells $(\mathrm{Control})\left({ }^{\star} P<0.01\right)$. PGP, protein gene product; RMP, resting membrane potentials.

or SARAF-overexpressing ICCs, we strongly suggest that these two proteins can act as essential regulators of pacemaker activity by modulating $\mathrm{ER} \mathrm{Ca}^{2+}$ concentration in ICCs.

SOCE can be initiated by receptor activation at the PM. Receptor activation leads to $\mathrm{Ca}^{2+}$ release from the ER and this activates $\mathrm{Ca}^{2+}$ influx at the $\mathrm{PM} .{ }^{8}$ Previous studies showed that ICCs possess various receptors for endogenous substances and activation of various receptors by agonists ( $\mathrm{CCh}$, substance $\mathrm{P}$, etc) that could influence $\mathrm{Ca}^{2+}$ release from ER stores, ${ }^{29,30}$ resulting in the conversion of a pacemaker current into tonic inward currents in ICCs. These phenomena could be blocked by exposure to a $\mathrm{Ca}^{2+}$ free solution. This indicates the possibility that ICCs have a SOCE system. As is shown in Figure 1, we confirmed the action of $\mathrm{CCh}$ on pacemaker activity in ICCs and found tonic pacemaker potential upon $\mathrm{CCh}$ treatment.

There are 2 essential components for SOCE activation: STIM1 in the ER and Orail in the PM. ${ }^{13,31,32}$ STIM1 is the $\mathrm{Ca}^{2+}$ sensor in the ER that measures $\mathrm{Ca}^{2+}$ depletion in the ER. Upon $\mathrm{Ca}^{2+}$ store depletion, STIM1 binds with the Orail channel in the $\mathrm{PM}$, resulting in $\mathrm{Ca}^{2+}$ influx through Orail. ${ }^{33}$ We speculate the existence of a $\left[\mathrm{Ca}^{2+}\right]_{\mathrm{i}}$ modulating component like STIM1 in ICCs because ICCs have spontaneous electrical activity by $\left[\mathrm{Ca}^{2+}\right]_{\mathrm{i}}$ oscillation and various receptors are activated via $\left[\mathrm{Ca}^{2+}\right]_{\mathrm{i}}$ regulation. As shown in Figure 2, we found that overexpressing STIM1 ICCs by 
A

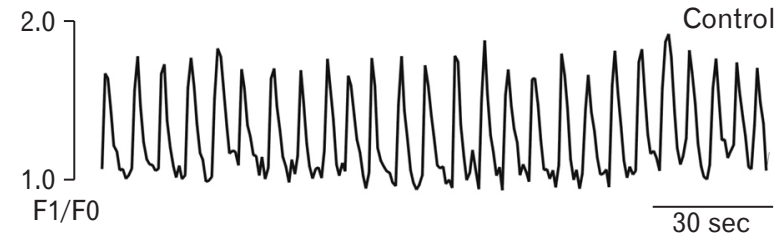

B

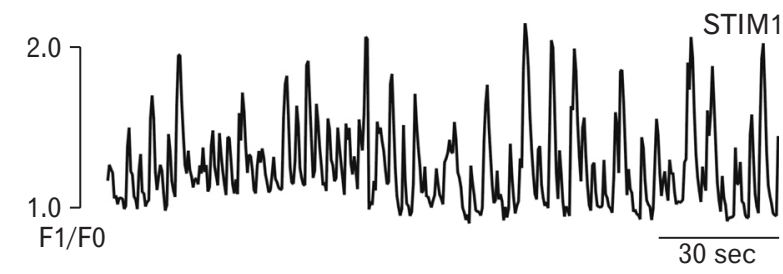

C

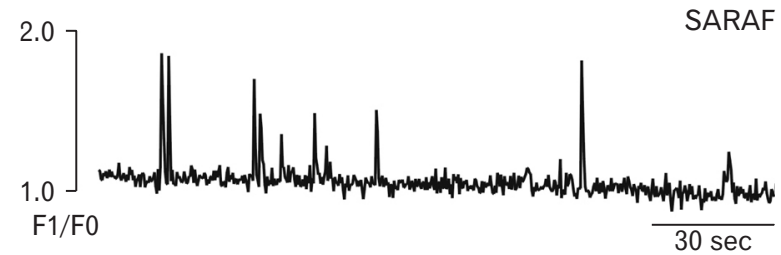

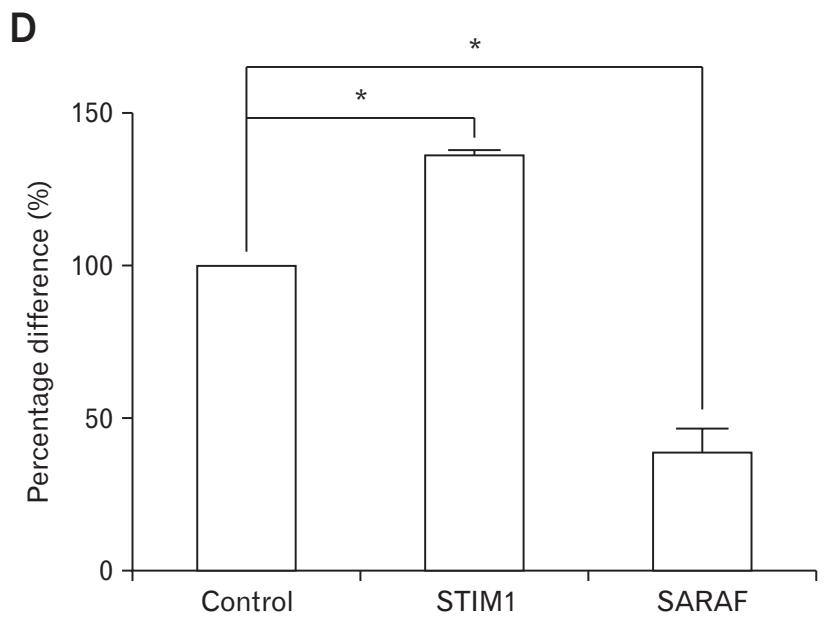

Figure 5. Effects of stromal interaction molecule 1 (STIM1) or store-operated calcium entry-associated regulatory factor (SARAF) overexpression in cultured interstitial cells of Cajal (ICCs) from mouse small intestine on intracellular calcium ions $\left(\mathrm{Ca}^{2+}\right.$ ) oscillation. (A-C) Fluorescence intensity changes in cultured mouse ICCs overexpressing empty vector (A), STIM1 (B), or SARAF (C). Horizontal solid lines represent the scale of fluorescence intensity change duration. Pacemaker potential responses in STIM1- or SARAF-overexpressing ICCs are summarized in (D). The bars represent percentage difference. Asterisks represent significant differences from the empty-vector expressing control (Control) $\left({ }^{\star} P<0.01\right)$. The variations of intracellular $\mathrm{Ca}^{2+}$ fluorescence emission intensity were expressed as $\mathrm{F} 1 / \mathrm{F} 0$, where $\mathrm{F} 0$ represents the intensity of the first image and counted the peak points as frequency.

transfection resulted in a dramatically increased frequency of pacemaker activity in these cells. Furthermore, fused pacemaker peaks were observed, possibly due to overlapping pacemaker activity as a result of the increased frequency. This suggests that the frequency of pacemaker activity in ICCs is decided by $\mathrm{Ca}^{2+}$ concentration in the ER, and that STIM1 can be a modulator for this in ICCs. Furthermore, exposure to $\mathrm{Gd}^{3+}$ that is considered as a relative inhibitor of SOCE or $\mathrm{Ca}^{2+}$-free solution blocked pacemaker activity and CCh-induced action. ${ }^{34}$ Although $\mathrm{Gd}^{3+}$ is not a specific blocker for SOCE channels like Orai, these results provide the possibility that SOCE can be involved in the pacemaker mechanism in ICCs. To verify this, a future study should aim to confirm the interaction between Orail and STIM1 in ICCs.

Recently, the ER protein SARAF was reported. It is well known that $\mathrm{SARAF}$ is a negative regulator of SOCE. ${ }^{16}$ In addition, SARAF is located in the ER membrane where it interacts with STIM1. In resting states, SARAF binds STIM1 and prevents STIM1-Orail activation. Upon ER $\mathrm{Ca}^{2+}$ depletion, SARAF is dissociated from STIM1 and STIM1-Orail is activates. ${ }^{33}$ We found that SARAF-overexpressing ICCs exhibited decreased pacemaker activity frequency. This can be explained because SARAF blocks refilling and decreases the concentration of $\mathrm{ER} \mathrm{Ca}^{2+}$. Namely, the STIM1-Orail interaction required for refilling ER $\mathrm{Ca}^{2+}$ is interrupted by high SARAF expression in ICCs, and ICCs therefore could not initiate $\left[\mathrm{Ca}^{2+}\right]_{\mathrm{i}}$ oscillation to generate pacemaker activity.

The last question we asked is do STIM1 or SARAF really regulate $\left[\mathrm{Ca}^{2+}\right]_{\mathrm{i}}$ mobilization? The inositol 1,4,5-triphosphate receptor plays a role in generating spontaneous electrical activity in ICCs, and periodic $\mathrm{Ca}^{2+}$ release from intracellular $\mathrm{Ca}^{2+}$ stores produces $\left[\mathrm{Ca}^{2+}\right]_{\mathrm{i}}$ oscillations in ICCs from mouse ileum. These actions seen in ICCs are considered to be the primary pacemaker activity in the GI tract. ${ }^{22}$ In our study, we found that STIM1 or SARAF overexpression modulated ICC $\left[\mathrm{Ca}^{2+}\right]_{\mathrm{i}}$ directly (Fig. 5). This is important evidence that STIM1 or SARAF can modulate $\left[\mathrm{Ca}^{2+}\right]_{\mathrm{i}}$ and this results in an alteration of pacemaker activity frequency in ICCs.

In the GI tract, the patterns of slow waves or pacemaker activity vary by location. This variety can be explained by mechanisms 
of smooth muscle, ICCs, or enteric nerves. However, this study also provides evidence that the degree of $\mathrm{ER}$ protein expression can determine the frequency of pacemaker activity. Furthermore, this influence may modulate slow waves generated from smooth muscles. In conclusion, this study suggests the possibility that the representative ER proteins, STIM1 and SARAF, exist in ICCs and can modulate pacemaker activity. Additionally, $\mathrm{Ca}^{2+}$ concentration in ER stores may determine the frequency of pacemaker activity.

Financial support: This study was supported by a grant from Chosun Hospital in 2015.

\section{Conflicts of interest: None.}

Author contributions: Chan Guk Park and Mei Jin Wu designed research; Chan Guk Park, Mei Jin Wu, Chansik Hong, Ju Yeon Jo, Han Yi Jiao, Hyun Park, and Jae Yeoul Jun performed research; and Jae Yeoul Jun and Seok Choi wrote the paper and contributed to the experiment determination.

\section{References}

1. Schwaller B. The regulation of a cell's $\mathrm{Ca}^{2+}$ signaling toolkit: the $\mathrm{Ca}^{2+}$ homeostasome. Adv Exp Med Biol 2012;740:1-25.

2. Grienberger $C$, Konnerth A. Imaging calcium in neurons. Neuron 2012;73:862-885.

3. Berridge MJ. Calcium signaling remodeling and disease. Biochem Soc Trans 2012;40:297-309.

4. Bojarski L, Herms J, Kuznicki J. Calcium dysregulation in Alzheimer's disease. Neurochem Int 2008;52:621-633.

5. Targos B, Baranska J, Pomorski P. Store-operated calcium entry in physiology and pathology of mammalian cells. Acta Biochim Pol 2005;52:397409.

6. Kiselyov K, Wang X, Shin DM, Zang W, Muallem S. Calcium signaling complexes in microdomains of polarized secretory cells. Cell Calcium 2006; 40:451-459.

7. McCarron JG, Chalmers S, Bradley KN, MacMillan D, Muir TC. $\mathrm{Ca}^{2+}$ microdomains in smooth muscle. Cell Calcium 2006;40:461-493.

8. Parekh AB, Putney JW Jr. Store-operated calcium channels. Physiol Rev 2005;85:757-810.

9. Feske S, Gwack Y, Prakriya M, et al. A mutation in Orail causes immune deficiency by abrogating CRAC channel function. Nature 2006; 441:179-185.

10. Peinelt C, Vig M, Koomoa DL, et al. Amplification of CRAC current by STIM1 and CRACM1 (Orai1). Nat Cell Biol 2006;8:771-773.

11. Prakriya M, Feske S, Gwack Y, Srikanth S, Rao A, Hogan PG. Orail is an essential pore subunit of the CRAC channel. Nature 2006;443:230233.
12. Roos J, DiGregorio PJ, Yeromin AV, et al. STIM1, an essential and conserved component of store-operated $\mathrm{Ca}^{2+}$ channel function. J Cell Biol 2005;169:435-445.

13. Baba Y, Hayashi K, Fujii Y, et al. Coupling of STIM1 to store-operated $\mathrm{Ca}^{2+}$ entry through its constitutive and inducible movement in the endoplasmic reticulum. Proc Natl Acad Sci USA 2006;103:16704-16709.

14. Yuan JP, Zeng W, Dorwart MR, Choi YJ, Worley PF, Muallem S. SOAR and the polybasic STIM1 domains gate and regulate Orai channels. Nat Cell Biol 2009;11:337-343.

15. Zhou Y, Meraner P, Kwon HT, et al. STIM1 gates the store-operated calcium channel ORAI1 in vitro. Nat Struct Mol Biol 2010;17:112-116.

16. Palty R, Raveh A, Kaminsky I, Meller R, Reuveny E. SARAF inactivates the store operated calcium entry machinery to prevent excess calcium refilling. Cell 2012;149:425-438.

17. Kobayashi S, Chowdhury JU, Tokuno H,Nahar S, Iino S. A smooth muscel nodule producing 10-12cycles/min regular contractions at the mesenteric border of the pacemaker area in the guinea-pig colon. Arch Histol Cytol 1996;59:159-168.

18. Huizinga JD, Thuneberg L, Klüppel M, Malysz J, Mikkelesen H, Bernstein A. W/kit gene required for interstitial cells of Cajal and for intestinal pacemaker activity. Nature 1995;373:347-349.

19. Sanders KM, Ordög T, Koh SD, Torihashi S, Ward SM. Development and plasticity of interstitial cells of Cajal. Neurogastroenterol Motil 1999;11:311-338.

20. Sanders KM. A case for interstitial cells of Cajal as pacemaker and mediators of neurotransmission in the gastrointestinal tract. Gastroenterology 1996;111:492-515.

21. Suzuki H, Takano H, Yamamoto Y, et al. Properties of gastric smooth muscles obtained from mice which lack inositol triphosphate receptor. J Physiol 2000;525(Pt 1):105-111.

22. Yamazawa T, Lino M. Simultaneous imaging of $\mathrm{Ca}^{2+}$ signals in interstitial cells of Cajal and longitudinal smooth muscle cells during rhythmic activity in mouse ileum. J Physiol 2002;538(Pt 3):823-835.

23. Torihashi S, Fujimoto T, Trost C, Nakayama S. Calcium oscillation linked to pacemaking of interstitial cells of Cajal: requirement of calcium influx and localization of TRP4 in caveolae. J Biol Chem 2002;277:1919119197.

24. Choi S, Yeum CH, Chang IY, et al. Activating of ATP-dependent $\mathrm{K}^{+}$ channels comprised of Kir 6.2 and SUR 2B by $\mathrm{PGE}_{2}$ through EP2 receptor in cultured interstitial cells of Cajal from murine small intestine. Cell Physiol Biochem 2006;18:187-198.

25. Kim BJ, Lim HH, Yang DK, et al. Melastatin-type transient receptor potential channel 7 is required for intestinal pacemaking activity. Gastroenterology 2005;129:1504-1517.

26. Zhu MH, Kim TW, Ro $\mathrm{S}$, et al. $\mathrm{A} \mathrm{Ca}^{2+}$-activated $\mathrm{Cl}^{-}$conductance in interstitial cells of Cajal linked to slow wave currents and pacemaker activity. J Physiol 2009;587(Pt 20):4905-4918.

27. Zheng H, Park KS, Koh SD, Sanders KM. Expression and function of a T-type $\mathrm{Ca}^{2+}$ conductance in interstitial cells of Cajal of the murine small intestine. Am J Physiol Cell Physiol 2014;306:C705-C713.

28. Nakayama S, Torihashi S. Spontaneous rhythmicity in cultured cell clusters isolated from mouse small intestine. Jpn J Physiol 2002;52:217-227. 
29. So KY, Kim SH, Sohn HM, et al. Carbachol regulates pacemaker activities in cultured interstitial cells of Cajal from the mouse small intestine. Mol Cells 2009;27:525-531.

30. Jun JY, Choi S, Yeum CH, et al. Substance P induces inward current and regulates pacemaker currents through tachykinin NK1 receptor in cultured interstitial cells of Cajal of murine small intestine. Eur J Pharmacol 2004;495:35-42.

31. Liou J, Kim ML, Heo WD, et al. STIM is a $\mathrm{Ca}^{2+}$ sensor essential for $\mathrm{Ca}^{2+}$ store-depletion-triggered $\mathrm{Ca}^{2+}$ influx. Curr Biol 2005;15:12351241.
32. Yang X, Jin H, Cai X, Li S, Shen Y. Structural and mechanistic insights into the activation of Stromal interaction molecule 1 (STIM1). Proc Natl Acad Sci USA 2012;109:5657-5662.

33. Albarran L, Lopez JJ, Amor NB, et al. Dynamic interaction of SARAF with STIM1 and Orai1 to modulate store-operated calcium entry. Sci Rep 2016;6:24452.

34. Murtazina DA, Chung D, Ulloa A, et al. TRPC1, STIM1, and ORAI influence signal-regulated intracellular and endoplasmic reticulum dynamics in human myometrial cells. Biol Reprod 2011;85:315-326. 